First publ. in: Journal of Theoretical Politics 11 (1999), 1, pp. 75-106

\title{
EXPLORATIONS INTO THE VISUALIZATION OF POLICY NETWORKS
}

\author{
Ulrik Brandes, Patrick Kenis, Jörg Raab, Volker Schneider and \\ Dorothea Wagner
}

\begin{abstract}
Visualization is an important aspect of both exploration and communication of categorical as well as relational data. Graphical displays of policy networks are particularly attractive, since they enable authors to display in a compact way the relevant actors in a network, how they are related to each other, and what the overall structure looks like. Sociograms were early companions of social network analysis, but have received surprisingly little attention during the following decades. Only in the last few years has easy accessibility to quality computing and graphic equipment revived a now rapidly growing interest.

In this paper, we analyze the problem of visualizing policy networks. We first argue why network visualization is important and non-trivial. Then we show that current methods are somewhat ad hoc in their attempt to convey information contained in a network.

Our main contribution is a systematic approach to network visualization, closely following the general principles of information visualization. It provides a generic formalization which may serve as a guideline for further developments.
\end{abstract}

KEY WORDS • algorithm • network visualization • sociogram

\section{Introduction}

The introduction of the policy network concept has been one of the major innovations in policy analysis in recent years (Kenis and Schneider, 1991; Héritier, 1993; Börzel, 1997). An important method for describing and analyzing them is formal network analysis (Laumann and Knoke, 1987; Pappi et al., 1995). The main purpose of computer programs developed to conduct formal network analysis is to calculate their aggregate measures on centrality, density, etc. However, some of these programs also include an option for graphical presentation of the structure of the networks under study. Graphical displays are particularly attractive since they compactly display the relevant actors in a network and how these relate to each other. There are, of course, very different ways for visualizing the same policy

The authors acknowledge two anonymous referees for helping to improve the quality of this article with their useful comments and suggestions.

Konstanzer Online-Publikations-System (KOPS)

URL: http://www.ub.uni-konstanz.de/kops/volltexte/2008/7195/

URN: http://nbn-resolving.de/urn:nbn:de:bsz:352-opus-71951 
network just as there are different ways of calculating their structural characteristics or different ways of theorizing about them. Although there is considerably less literature on the problem of network visualization compared to the calculation of structural properties or on theorizing about policy networks, there are at least three reasons why the visualization aspect is important.

First, the function of network visualization goes far beyond 'illustration'. Network visualizations can help to improve communication about the data to third parties (such as policy-makers); it can help the researcher to explore specific properties of certain networks better or facilitate the exploration of differences across several networks; or it could even help to discover explanations for policies. ${ }^{1}$

Second, although numerous visualizations of social and policy networks can be found throughout the literature, systematic accounts of how visualizations are produced are very rare and, in general, techniques for creating visual representations of relational data have remained virtually unchanged since the study of social networks began (see Section 2.3).

Third, reflecting on the form and shape of visualized policy networks helps to critically evaluate existing ways of visualizing social networks (see Sections 2.2 and 3) as well as helps towards the development of objective standards of graphical excellence (see Section 4).

Ultimately, these contributions could and should be used as starting points for the implementation of formal instruments for appropriate visual presentation of social or policy networks, respectively, i.e. to develop automatic procedures for editing, analyzing, and presenting networks in a scientific way.

\section{Network Visualization Reviewed}

\subsection{The Importance of Network Visualization}

Data graphics can do much more than simply substitute for tabular descriptions: 'At their best, graphics are instruments for reasoning about quantitative information. Often the most effective way to describe, explore, and summarize a set of numbers - even a very large set - is to look at pictures of those numbers' (Tufte, 1983: 9). Graphical or visual presentations can not only describe data in different ways, but can also facilitate the comparison between different sets of data, stimulate scientific innovation, and even stimulate theoretical insights (Klovdahl, 1981; Müller, 1991).

In the case of network studies in general, and policy network analysis in

1. On the basis of a number of historical examples, Tufte concludes: 'Those who discover an explanation are often those who construct its representation' (Tufte, 1997: 9). 
particular, visualization of quantitative data becomes a very important instrument. A simple description of relational data by means of tables is extremely limited in its explorative power (even if compared to tabular descriptions of categorical data).

In Figure 1 the adjacency matrix of a network of 14 political actors and their strong political ties (Doreian and Albert, 1989) is shown. Actors are labeled $\mathrm{A}$ to $\mathrm{N}$, and the row of one actor contains a one in the column of another if they have strong political ties, and a zero otherwise. The visual presentation of the same data is much easier to read when it comes to observing who is directly linked to whom, but it also reveals who is indirectly linked to whom - information which could otherwise only be recognized by experienced matrix readers. Given the fact that already a simple description of the data in the form of a matrix is difficult to read, it seems obvious that an exploration of the data through tables becomes practically impossible. ${ }^{2}$ In contrast, a visual presentation allows basic features of the network, as well as a great number of additional information on its structural characteristics, to be observed. For example, the visualization of the political network in Figure 1 already gives some indications regarding such important questions as: Which actor reaches

\begin{tabular}{|c|c|c|c|c|c|c|c|c|c|c|c|c|c|}
\hline & & & & & & & & & & & & & \\
\hline $\bar{A}$ & 0 & 0 & 1 & 1 & 0 & 0 & 1 & & $\begin{array}{lll}0 & 0\end{array}$ & 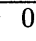 & 0 & 1 & \\
\hline B & 0 & 0 & 0 & 0 & 0 & 0 & 0 & & 11 & & 1 & 0 & \\
\hline C & 1 & 0 & 0 & 1 & 0 & 1 & 1 & & $\begin{array}{lll}0 & 0\end{array}$ & 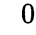 & 0 & 0 & \\
\hline D & & 0 & 1 & 0 & 1 & 1 & 1 & & $\begin{array}{lll}0 & 0\end{array}$ & 0 & 1 & 0 & \\
\hline $\mathrm{E}$ & 0 & 0 & 0 & 1 & 0 & 1 & 0 & & $\begin{array}{lll}0 & 0\end{array}$ & 0 & 0 & 0 & \\
\hline $\mathrm{F}$ & 0 & 0 & 1 & 1 & 1 & 0 & 0 & & $\begin{array}{lll}0 & 0\end{array}$ & 0 & 1 & 0 & \\
\hline G & 1 & 0 & 1 & 1 & 0 & 0 & 0 & & $\begin{array}{lll}0 & 0\end{array}$ & 0 & 0 & 0 & \\
\hline $\mathrm{H}$ & 0 & 1 & 0 & 0 & 0 & 0 & 0 & & 11 & 0 & 1 & 1 & \\
\hline I & 0 & 1 & 0 & 0 & 0 & 0 & 0 & & $\begin{array}{lll}0 & 1\end{array}$ & 0 & 0 & 1 & \\
\hline $\mathrm{J}$ & 0 & 1 & 0 & 0 & 0 & 0 & 0 & & 10 & 0 & 0 & 1 & \\
\hline $\mathrm{K}$ & 0 & 0 & 0 & 0 & 0 & 0 & 0 & 0 & $\begin{array}{lll}0 & 0\end{array}$ & 0 & 1 & 0 & \\
\hline L & 0 & 1 & 0 & 1 & 0 & 1 & 0 & 1 & $\begin{array}{lll}0 & 0\end{array}$ & 1 & 0 & 1 & \\
\hline $\mathrm{M}$ & 1 & 0 & 0 & 0 & 0 & 0 & 0 & & 11 & 0 & 1 & 0 & \\
\hline $\mathrm{N}$ & 0 & 0 & 1 & 0 & & 1 & 0 & & & 0 & 0 & 0 & \\
\hline
\end{tabular}

(a)

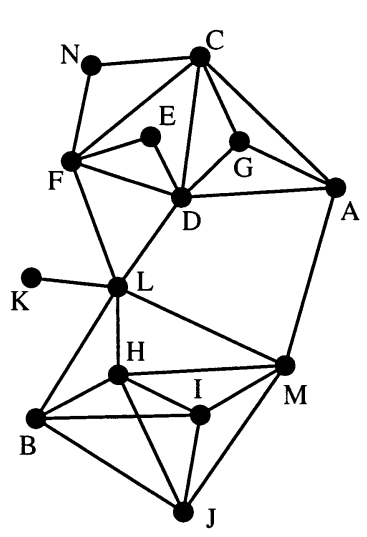

(b)

Figure 1. The Adjacency Matrix of a Political Network (Reproduced from Doreian and Albert, 1989). First Try to Explore the Network's Structure by Looking at its Matrix (a) and then Turn to its Graphical Presentation (b)

2. Some improvements are possible by simultaneously rearranging the rows and columns (see e.g. Katz, 1947). However, we do not discuss such restricted forms of graphical presentation, since they appear to be too limited to meet the general purpose discussed in Section 3. 
most other actors? Can every actor be reached by every other actor? Do some actors only interact with one another? Furthermore, if relational information could be combined with information on attributes of the actors in a visual display, other insights could be gained: Do actors with overlapping membership networks share values? Are there common behavioral patterns? Do actors with similar demographic characteristics interact more? Do communications between some actors flow in one direction only (hierarchy)?

Assuming that a network is indispensable, a number of questions arise:

1 . Does the way in which network data are visualized matter?

2. What has been developed in this area so far?

3 . Which principal procedures for visualizing networks have prevailed?

4. Are current methods satisfactory?

At least partial answers to the first three questions are given in the following subsections. The fourth question, and its implications, are the subject of the subsequent sections.

\subsection{Relative Effectiveness of Visualizations}

When Tufte (1983: 191) states that 'design is a choice' he means the graphics of the same data can look very different, and the quality may vary. Consequently, since visualization has tremendous explorative and communicative power and is not merely an instrument with which to decorate numbers, some analysis should be invested into what determines quality in a visualized data matrix.

One problem is that there is little reliable work since not one piece of literature is known to us that deals with the quality of network visualization, even though there is a proven effect on perception. ${ }^{3}$ Whilst there are a number of interesting articles addressing the question of network visualization, these concentrate on 'technological' innovations to visualize networks. Examples include new computers, new printers, specific software packages, specific programming languages, new algorithms, increased processing capabilities of computers enabling color, 3D and moving representations (see, e.g., Klovdahl, 1981; Freeman, 1996, 1997). Although these devices are important components for permitting visualizations, they do not themselves define quality. ${ }^{4}$

3. Blythe et al. (1995) conduct a study proving the effect of node positioning on perception of network measures. Other studies (Purchase et al., 1995; Purchase, 1997) emphasize a presentation's general effect on the understanding of network structure. Note that Bertin (1983) does not reason about any particular, but arbitrary kinds of networks.

4. One might even argue that computers have generally led to a decrease in quality (see, for example, the many examples of computer-produced 'chartjunk' graphs presented by Tufte [1983] in contrast to the graph produced by Charles Joseph Mainard in 1869, which may be 'the best statistical graphic ever drawn' [Tufte 1983: 41]). 
Figure 2 (from Tufte, 1983) clearly shows how the same data can be presented in very different ways. Not only does the second graph yield a much calmer view, removing irrelevant information, it also does not generate the false impression of a substantial and continuous increase in spending. As Tufte convincingly shows, the first graph deploys several visual and statistical tricks - all working in the same direction, to exaggerate the budget which does not really increase when put in relation to population size. This is not the place to uncover the underlying graphical gimmicks (see Tufte, 1983, 66-9) but rather to illustrate the point that not every way of visualization is equally useful. Tufte's principles of graphical excellence are the following:

- Graphical excellence is the well-designed presentation of interesting data - a matter of substance, of statistics, and of design.

- Graphical excellence consists of complex ideas communicated with clarity, precision, and efficiency.

- Graphical excellence is what gives to the viewer the greatest number of ideas in the shortest time with the least ink in the smallest space.

- Graphical excellence is almost always multivariate.

- Graphical excellence requires telling the truth about the data.

In the same way that graphical presentations of categorical data differ in quality, so do graphical presentations of relational data. Consider the graphical presentations of a political network in Figure 3, which can be considered representative of current forms of social network visualization. They illustrate that Tufte's principles of graphical excellence are violated. This may have a number of reasons. First, it could be that the quality of visualization is not taken seriously. Second, it could be that the criteria drawn from the field of categorical data cannot be applied in the same way to relational data. For example, in many visual presentations of nonweighted matrices (like Figure 3a) the length of the links drawn varies significantly. This heavily violates Tufte's principle of telling the truth about the data, because although every link means the same (i.e. the presence of a link with a score of 1 ), they are presented in different ways. Whereas this principle can easily be implemented in the case of categorical data, we see later that it cannot usually be satisfied with relational data. A third reason could be that the information which should be communicated ${ }^{5}$ is very different from the information to be communicated with categorical data.

Consequently, although one can expect that in the case of relational data visualization some presentations are also more effective than others, it is now apparent that we do not have evaluation techniques to guarantee the

5. Interesting aspects of the network shown in Figure 3 are that the actors belong to two different camps, and that there is one highly central actor (Doreian and Albert, 1989). 
(a)

New York State Total Budget Expenditures and Aid to Localities In billions of dollars

Fiscal 1966-1976

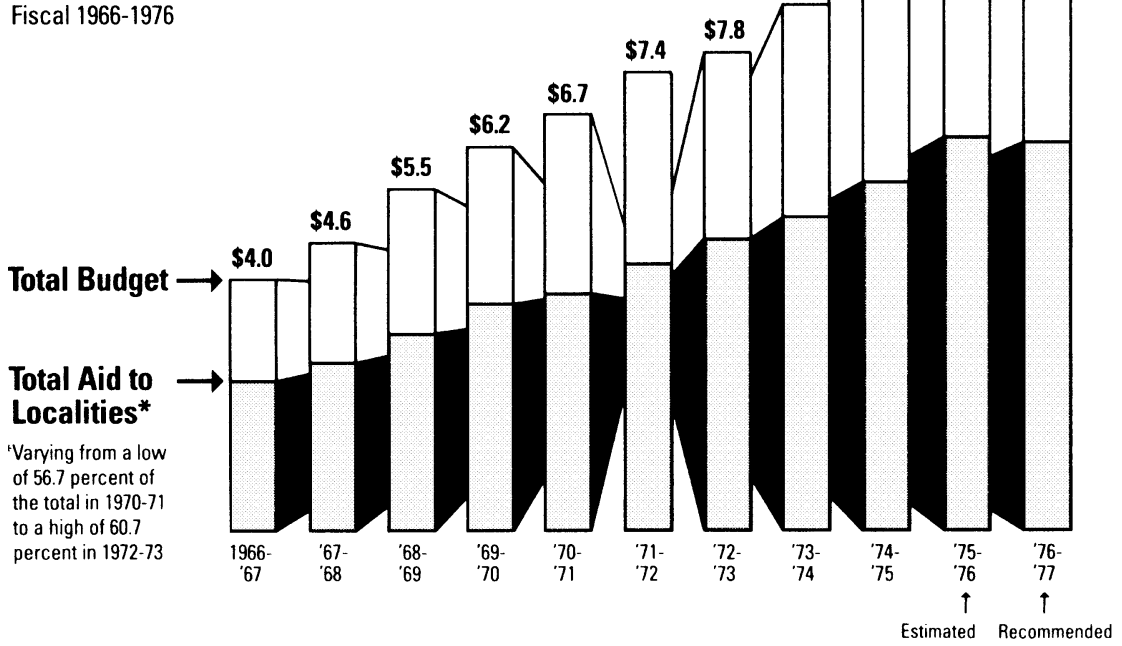

Per capita

(b)

budget expenditures,

in constant dollars

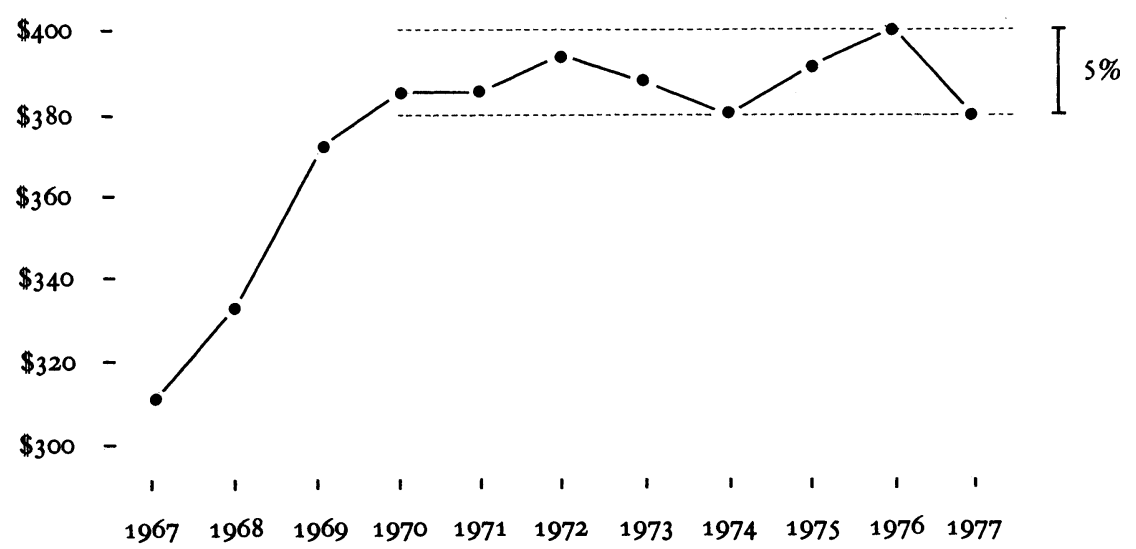

Figure 2. From Chartjunk to Graphical Excellence (Tufte, 1983: 66-8). Two Versions of New York Total Budget Expenditure and Aid to Localities 


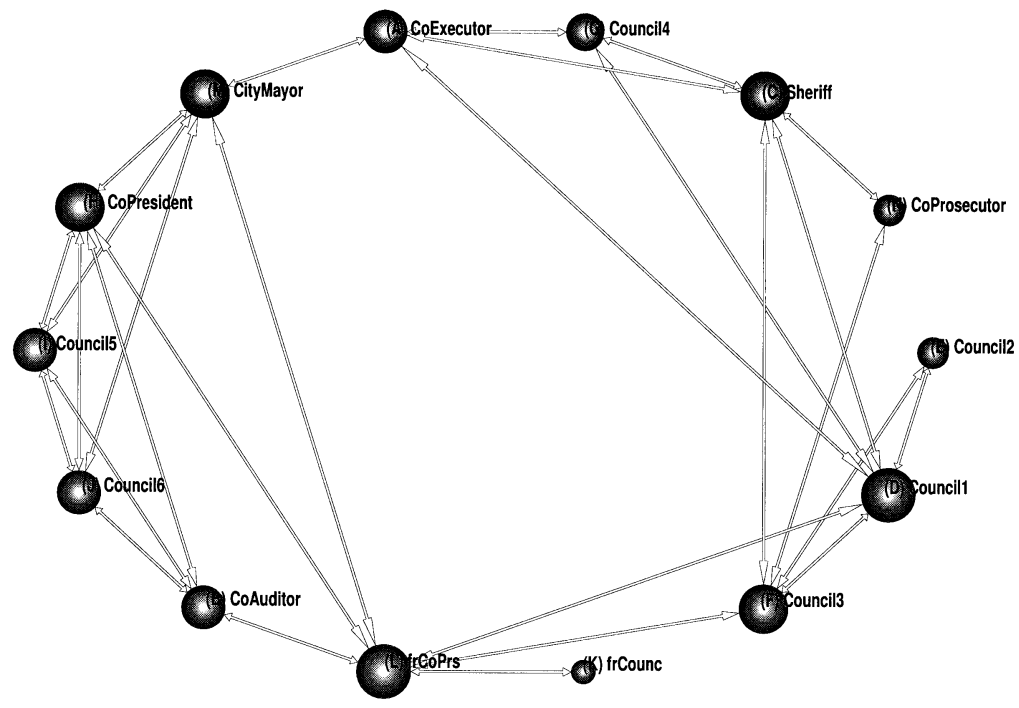

(a)

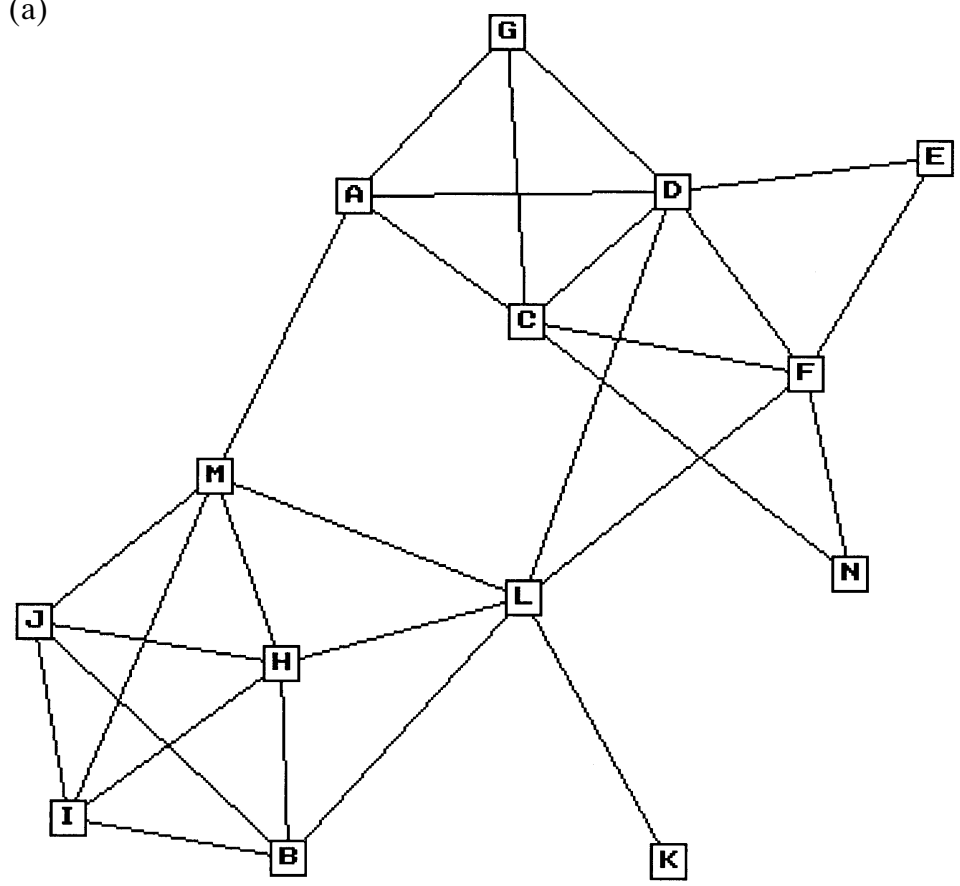

(b)

Figure 3. Two Visualizations of the Network from Figure 1 found in the Literature: (a) is from Krempel (1993), while (b) appears in Freeman (1996) 
quality of visualizations. The remainder of this article aims at laying a base for such a discussion.

\subsection{A Short History of Network Visualization}

Given the importance of graphical representation for scientific development, it is astonishing how little attention the subject has received. Klovdahl's (1981) conceptual article 'A Note on Images of Networks' is one of the rare publications about this subject. Although interesting and very much to the point, it was cited only four times between 1981 and 1996. ${ }^{6}$ The following outline mainly summarizes Klovdahl's overview on the history of network visualization.

The sociogram, a visual representation of relational sociological data used by Moreno in the 1930s, was one of the earliest techniques for formalizing social configurations (see Moreno, 1953) influencing - directly or indirectly - a number of subdisciplines of the social sciences (social psychology, social anthropology, sociology of organization). One of the major investigations popularizing this approach was the Hawthorne study in which sociograms were used to describe social relations (Scott, 1991: 18). In the diagrams from this study, actors are represented by circles placed on horizontal lines indicating their status, and the presence of a relationship of certain type is shown by an arrow. The layout of the diagrams seem to be influenced by organization charts and electrical wiring plans (see Roethlisberger and Dickson, 1939: 500ff., or Figure 4 for an example). Although these early forms of graphical representation were a great help in the structural analysis of society at all levels (from school classes to elite structures at both local and national levels) and were considered a fruitful method of exploration, there had been very few improvements until the computer age opened up a completely new range of visualization possibilities. Before the broader introduction of computers, the researcher had to draw the images by hand in a very tiresome and time-intensive trial and error process until the image was satisfying. Two major types of representation had been developed at that time for the design of sociograms. First, arrow diagrams were drawn in which the most central actors were placed in the middle of the sheet and the researcher tried to reduce the number of cross-cutting connections as far as possible to achieve the best visual clarity. This idea was extended by Northway (1940), who introduced a variation in which nodes were grouped according to their centrality and then placed on concentric circles. The less central a node the farther outside it is placed (Klovdahl, 1981: 200). Second, from the attempt to reduce the number of cross-cutting connections, a common technique constructed the sociogram around the circumference of a circle, so all links

6. According to the Social Science Citation Index. 


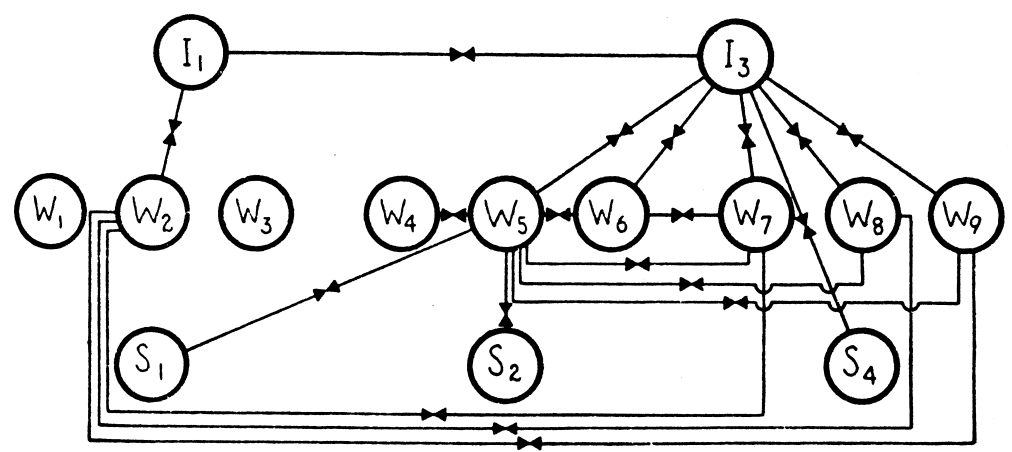

Figure 4. Historical Example of a Sociogram (Roethlisberger and Dickson, 1939) Copyright (C) 1939 by the President and Fellows of Harvard College. Reprinted by permission of Harvard University Press.

could be drawn inside it. Sometimes, different shapes and descriptors (see Figure 4) for nodes were used to represent attributes. In the 1960s, the first three-dimensional images were drawn (Laumann, 1966).

Since the 1970s a number of computer programs have been written that automatically generate visual presentations of relational data sets (Kadushin, 1974; Levin, 1976; Klovdahl, 1986; for more recent developments see Section 3). In general, visualization concepts and techniques coevolved with the elaboration of the tool of relational analysis in the social sciences which during the late 1970s and early 1980s had increasingly been covered under the label 'social network analysis'. This type of structural analysis combines specific mathematical and statistical techniques to compute indices for network positions and total network structures with multipurpose methods like multi-dimensional scaling (MDS) or cluster analysis. Therefore it is no surprise that parallel to the development and application of computer programs for sociograms MDS has been used since the 1970s by a number of authors either to visualize the proximity and centrality of actors on the basis of their path distances or the similarity of their relational profiles (for example, Laumann and Knoke, 1987; Laumann and Pappi, 1976). Visualization techniques, like the concepts used for the analysis of policy networks, evolved from social network analysis.

\subsection{Principal Procedures in Policy Network Visualization}

When applying the term 'policy network' in political science, a researcher takes at least one basic assumption for granted: 'configurational' structure in policy, politics, and polity matters. Modeling social structures as 'networks' means choosing nodes and links as the basic units of analysis. In policy network or policy processes analysis the nodes generally represent 
political actors - usually corporate actors (organizations) - but may also represent events or issues in a policy process. Links (edges) may represent different types of relations, such as communication, participation, resource exchange, social and political support, influence reputation, or status relations.

If one indeed agrees that these kinds of sociopolitical structures matter by restricting, and likewise enabling, actors in their behavior (Knoke, 1990a), the precise description and detailed analysis of such relational structures are important steps in political analysis. However, political action and interaction is influenced not only by the actors' relationships with one another but also by their attributes such as legal form, size, organizational type, age of the organization, resources, interests, attitudes towards political issues, tasks, functions, and nationality. Relational analysis is therefore often combined with the analysis of categorical data.

There is a small but growing family of quantitative studies on policy networks. Most of these use graphical forms - besides matrices and tables in the presentation of data and analytical results. At least four visualization methods are currently in use. One is the sociogram, which is the most intuitive way of presenting the structural positions of individual actors as well as their subgroupings in an overall configuration. Since the number of actors that can be displayed in a sociogram is severely limited, the MDS scattergram is taken as an alternative solution, which displays the actor positions only in a two- or three-dimensional space without actually drawing the lines of their interconnections. Further techniques such as the dendrogram and the Venn diagram are simple ways to represent the hierarchical subgroupings of actors according to some criteria of similarity or dissimilarity in their relational profile or their affiliations in the same network subgroups (e.g. cliques, cores, clans, etc.). The following is a list of what seem to be the four most common methods of visualizing policy network data, with citations of policy network studies using them (see also Figure 5):

- the sociogram (e.g. Doreian and Albert, 1989; Mayntz, 1993, 1994; Pappi, 1995; Pappi et al., 1995; Krempel, 1997);

- the MDS scattergram (e.g. Knoke, 1990b, for an application in international relations; Laumann and Pappi, 1976; Laumann and Knoke, 1987; Manigart, 1986; Schneider, 1992, 1993; Schneider and Werle, 1991);

- the dendrogram (e.g. Schneider, 1988; Scarini, 1996); and

- the Venn diagram (e.g. Kriesi, 1982).

The small number of examples of publications with images of policy networks reflects the fact that so far only a few quantitative policy network studies have been conducted. 


\section{Fundamental Aspects of Visualization and the State of the Art}

In the previous sections, it was argued that visualization is an important, non-trivial component of network analysis. Even though a fair amount of computer software is available to facilitate graphical editing, and even automatic layout of networks, the state of the art is too heuristic to be satisfactory. This argument is grounded in the long-established principle that every type of information visualization should be accomplished according to an appropriately defined mapping of data to graphics. Even though this may seem a trivial statement, we indicate in this section how common methods for visualizing networks disregard some of the consequences arising from this principle. A systematic approach to overcoming such limitations is proposed in Section 4.

\subsection{The Three Aspects of Information Visualization}

Information visualization consists of an appropriate transformation of input data to output graphics (Bertin, 1983). That is, relevant information contained in the data is to be expressed by honestly generated visual clues. An ideal visualization would, in the simplest way, reveal the information, the whole information, and nothing but the information contained in the data. We therefore argue that a visualization method is acceptable only if it clearly identifies the relevant information, defines an appropriate mapping, and generates the image accordingly. We refer to these three aspects as substance, design, and algorithm, respectively.

Substance. The purpose of visualizing networks is the communication of substance, either to the researcher her/himself, or to third parties. The substance of policy network data is specific information about political structures.

Consequently, any network visualization should be concise and precise about the information it intends to communicate, and the means it uses to do so. Any 'open', i.e. unspecific, presentation of such data either produces a visual puzzle - or a 'crypto-graphical mystery' (Tufte, 1983) - or an ambiguous picture allowing many interpretations, some of which might even convey false information. In Section 4.1, we provide a list of the most important network measures, i.e. the typical substance of a network.

Design. Unlike the way it is commonly understood, design does not mean aesthetics, beauty, or elegance. As the British designer Terence Conran (1996) puts it, design incorporates 98 percent function and 2 percent aesthetics. The design of a visualized network is the specification of how its substance is mapped to graphical elements, which implies that the most 


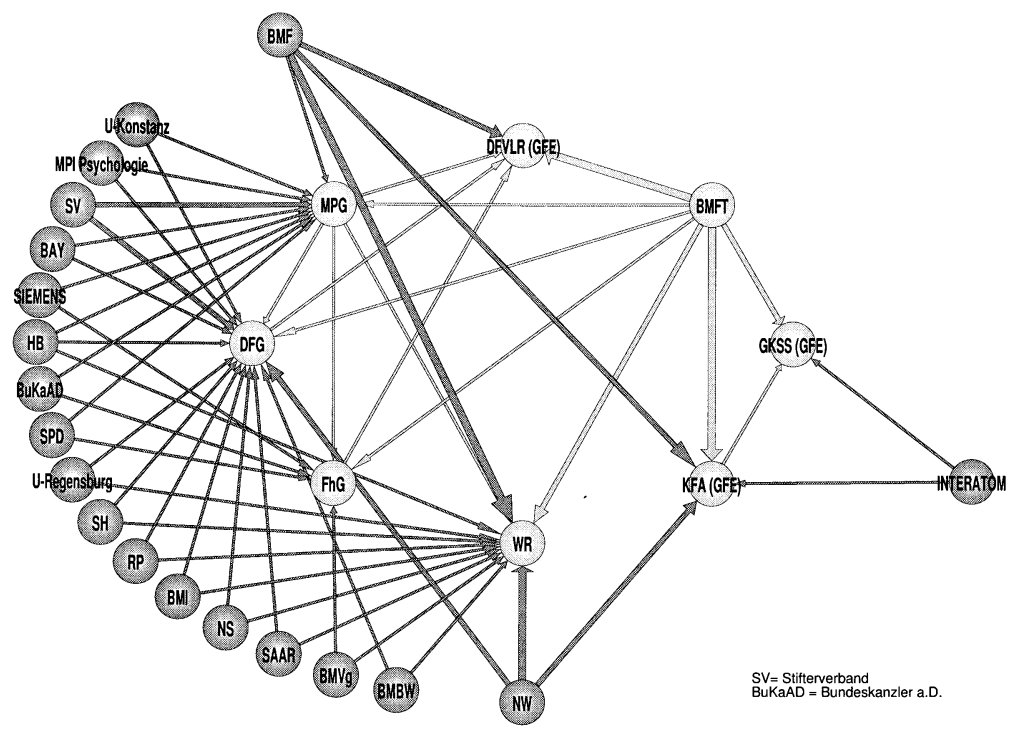

(a)

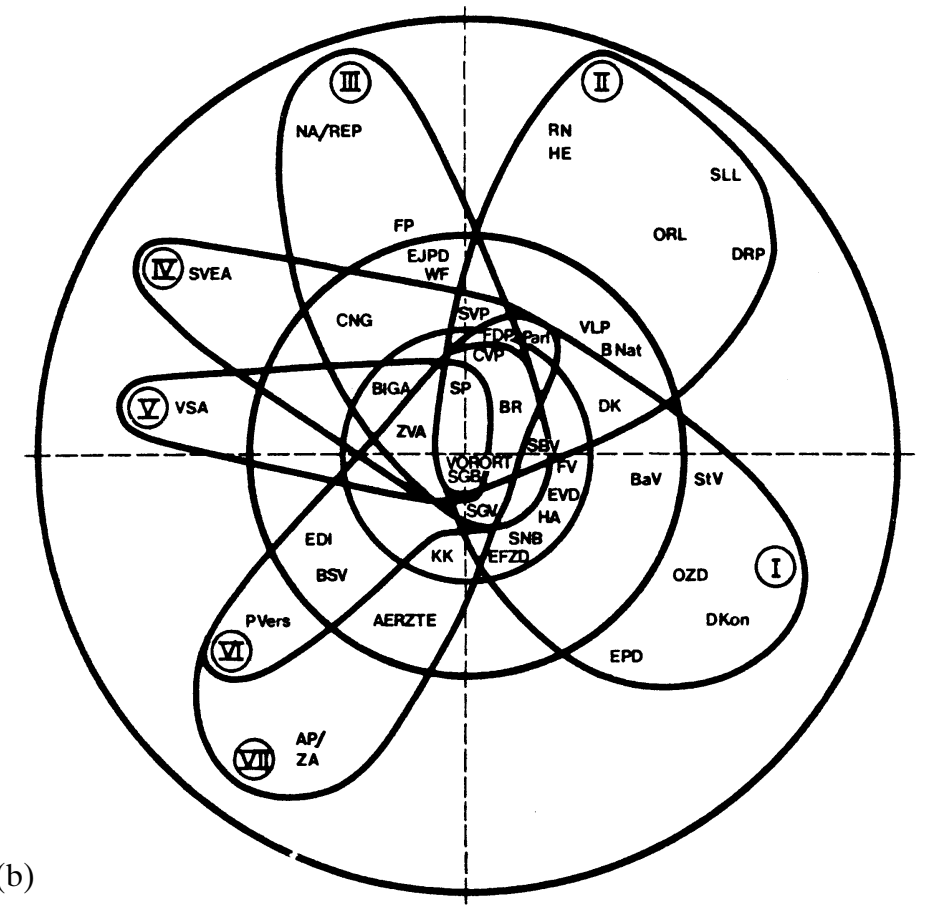

Figure 5. Examples of Four Different Types of Network Data Diagrams, taken from (a) Mayntz, 1994; (b) Kriesi, 1982 (Reprinted with permission) 


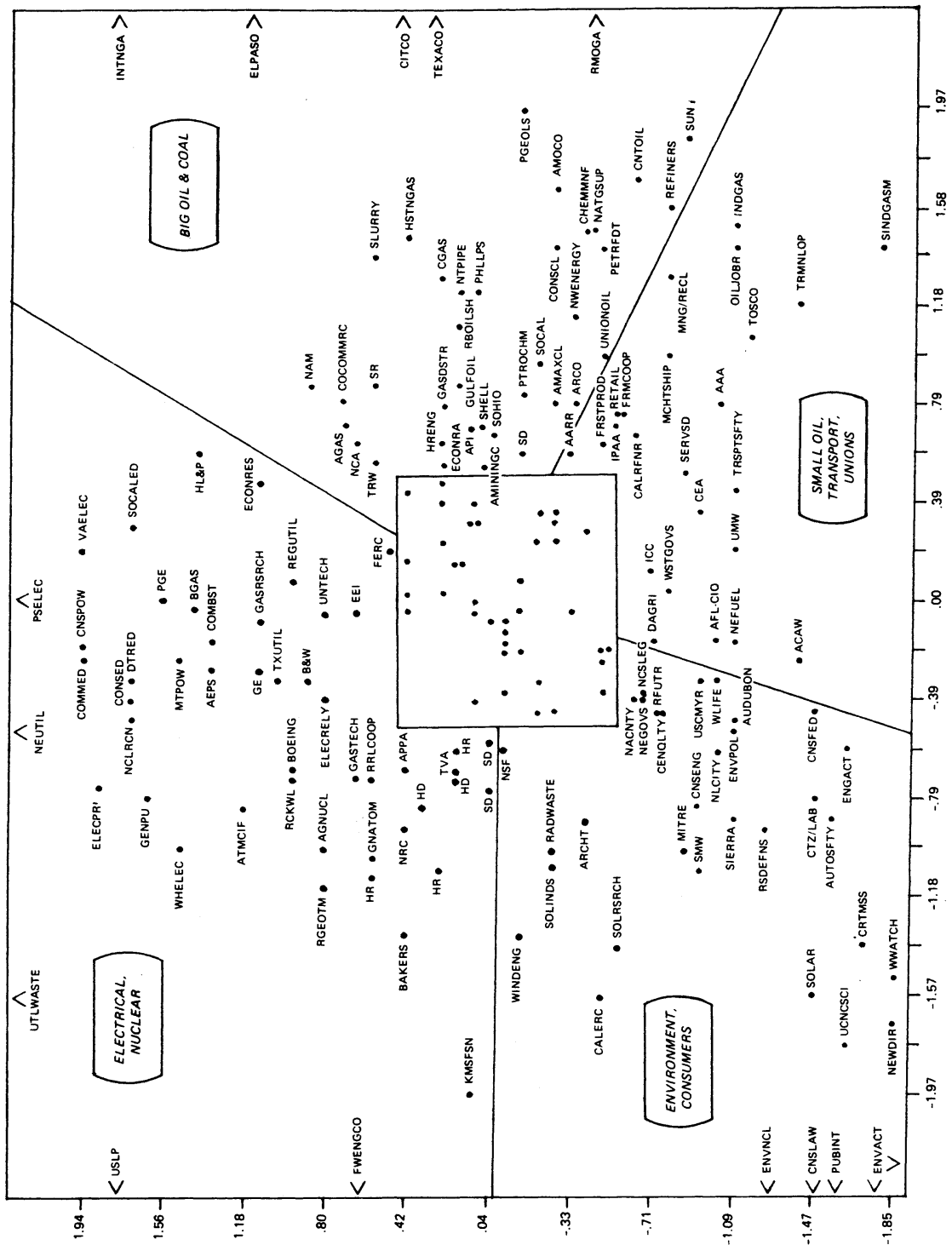

Figure 5. (c) Laumann and Knoke, 1987 (Reprinted with permission) 


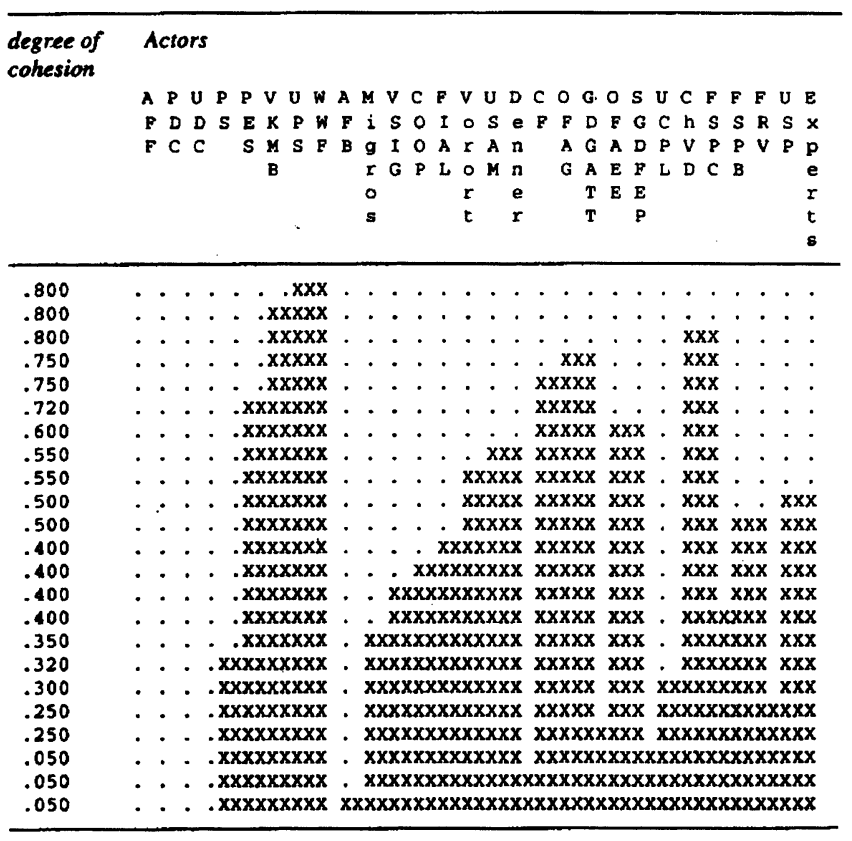

Figure 5. (d) Scarini, 1996 (Reprinted with permission)

important aspect of choosing a specification is the effective communication of substance, rather than a beautiful and impressive picture. On the other hand, aesthetics may well play a role in speeding up the perception process. We call the ease of reading the ergonomy of a visualization. The effectiveness of a design depends on how easily the substance is recognized in a visualization. Section 4.2 elaborates on the process of design specification.

Algorithm. The procedures used to realize a design specification for the substance of a given network constitute an aspect that is commonly overlooked. It is not often realized that, in many cases, perfect satisfaction of design requirements is impossible. ${ }^{7}$ Thus, even the best possible - with respect to some deviation measure - realization of a design may introduce artifacts or misleading arrangements. Moreover, existing approaches often use an algorithm that does not implement a specified design but implicitly defines one. Hence, it is important to be aware of the algorithm and its

7. Consider, for example, a design that requires all lines connecting different actors to be of the same length. This is a very reasonable requirement, when each link has exactly the same meaning. However, for many networks such a drawing does not exist. Moreover, it is difficult to decide whether it exists or not (Johnson, 1982). 
peculiarities which underlie a visualization process. Some more detail is given in Section 4.3.

\subsection{Current Approaches to Network Visualization}

Nowadays, approaches to network visualization try to make use of what is available rather than stating what is desired and then asking for tools implementing these requirements. Consequently, recent work on visualization orients itself towards the applicability and usefulness of existing computer software. Here, we argue that the tools commonly used do not properly identify all three of the aspects previously described.

The tools available for network visualization fall roughly into four categories: general purpose graphical editors, two kinds of drawing programs not specifically developed for social networks, and tools and strategies designed for visualizing social networks. The last category is most interesting because, from a formal point of view, the substance of policy and social networks are comparable (see Section 4.1).

General purpose graphical editors. They are the least comfortable, yet most flexible, tools, and are available for virtually every computer platform. They provide a rich set of editing functions, but almost no features tailored to networks. For example, when an actor is moved on the screen, its links are not moved accordingly because the program does not know about structural issues. The burden of specifying and implementing graphical design is placed on the user. Moreover, 'manual' generation of a graphical presentation, even for networks of moderate size, is a tedious, if not intractable, task.

Network drawing software from other disciplines. We distinguish two such categories. One consists of those programs that draw specific networks though not social networks, like, for instance, molecule structures. ${ }^{8}$ These provide means to position the nodes of the network in certain, domaindependent ways. For example, the atoms and bonds of a molecule are arranged according to underlying energy laws. Obviously, such programs do not account for the substance of a policy network. And because of that, they clearly do not specify an effective design. Their usefulness is limited to the fact that they, in general, produce drawings that are pleasing from an ergonomic point of view.

The other category consists of general purpose network drawing software and it contains computer programs that typically are domain independent graph layout programs - programs that arrange the nodes and

8. See MOVIEMOL (http://chem-www.mps.ohio-state.edu/ lars/moviemol.html) for a popular example. 
links of a network - offering a variety of algorithms for different layout styles (GRAPHLET, ${ }^{9}$ DAVINCI ${ }^{10}$ and many others). The design principles implemented by these algorithms are usually ergonomic requirements like small drawing area, number of line crossings, or number of bends in a line, that apply to any kind of network visualization. ${ }^{11}$ Again, they do not account for the substance of policy networks, and hence make no attempt to specify an effective design for it.

Software and strategies for social networks. This category comprises, for example, routines for MDS (e.g. Kruskal and Wish, 1978) or spectral partitioning (e.g. Mohar, 1991; Richards and Seary, 1997), plots in analytical software packages, designated drawing programs for social networks, and the only living tradition of drawing sociograms that could be tracked down, circle diagrams.

MDS and spectral partitioning are arguably the strategies in network visualization for which substance, design, and algorithm are most clearly identified. Both produce scattergrams: MDS plots reflect proximity in higher dimensional data (e.g. path distances) in fewer dimensions, and spectral partitioning plots are produced according to eigenvectors of certain network related matrices. Both methods take on a very distinguished interpretation of a network's substance and therefore either they display one aspect of it or we must assume that all the information contained in the network is comprehensible from Euclidean distances, which form the basic information in a scattergram. The stress value (Kruskal and Wish, 1978) of an MDS provides a measure of how well the plot fits the design ('map proximity to Euclidean distances').

Drawing programs like KRACKPLOT ${ }^{12}$ (Krackhardt et al., 1994), PAJEK ${ }^{13}$ (Batagelj and Mrvar, 1997), or MultiNet ${ }^{14}$ are the most advanced tools available today. Besides actor positioning according to MDS and eigen decomposition, respectively, the first two also include refinements of the well-known Spring Embedder (Eades, 1984), a heuristic for laying out arbitrary kinds of networks. ${ }^{15}$ Here, the design is a function of the algorithm rather than the substance. However, it is interesting to note that applying these algorithms seems very reasonable, if the substance is defined to be proximity in terms of path distances. The implied design is

9. http://www.fmi.uni-passau.de/Graphlet/

10. http://www.informatik.uni-bremen.de/ inform/forschung/daVinci/daVinci.html

11. For a comprehensive survey on general graph layout see the annotated bibliography of Di Battista et al. (1994).

12. http://www.contrib.andrew.cmu.edu/ krack/

13. http://vlado.mat.uni-lj.si/pub/networks/pajek/default.htm

14. http://www.sfu.ca./ richards/

15. The basic idea is to consider the nodes of the network to be repelling rings. Those linked are joined by a spring and a positioning with low forces exerted on the rings is sought. 
then similar to the design of MDS with some additional ergonomic criteria, e.g. nodes being distributed more evenly in the layout space. Krempel (1997) uses a similar placement algorithm, but has no generally available tool to offer.

The idea of circle diagrams is to place the actor nodes on an imaginary circle, which was assumed to make the pattern of lines more visible (Scott, 1991: 149). This clearly defies any definition of substance. It is a design purely based on a doubtful ergonomic criterion (simplification through prescribed shape) and has proved confusing (Blythe et al., 1995). An extension to this design requires placing actors so that the total length of connecting lines is kept to a minimum (Krempel, 1993). Even though dense subgraphs then tend to cluster within small arcs, there is no precise definition of the substance thus revealed and no indication of whether this design is effective.

In summary, existing methods for policy network visualization do not clearly identify substance, design, and algorithm at the same time. The only exceptions are diagrams resulting from designated analytical tools, like MDS or eigen analysis. However, they disregard ergonomy and have a very limited definition of a network's substance. Because the designs of MDS and partitioning methods are combined with ergonomic criteria, spring embedder variants seem to point in the right direction. Unfortunately, the substance conveyed by their design is only implicitly defined. It might turn out that the ergonomic criteria incorporated (in particular uniform node distribution and uniform edge lengths) work well enough in displaying many interesting aspects of a network (such as symmetry, cohesive subgroups, brokers). For now, this remains an open question that can only be answered by careful analysis of what one wants to show and the synthesis of an appropriate design to which these procedures can then be compared, as well as by empirical validation. The following section provides a first step towards a sound basis for analysis and judgement.

\section{A Formal Approach to Network Visualization}

In the previous section, we divided the process of network visualization into three major components: substance, design, and algorithm. We now propose a framework that is intended to serve as a guideline in producing visualizations and, even more importantly, tools for automatic visualization of networks. The framework respects the subdivision in Section 3 and views graphical presentation as a semiotic system for visual communication (Krampen, 1990). Note that we do not propose a general solution to the problem of network visualization but a basis for the analysis and comparison of existing approaches and a starting point for future developments. 


\subsection{Network Substance}

The different methods and strategies of network visualization are highly contingent on the general aim of policy network analysis and its specific use of the general 'network analytic tool box' (Kenis and Schneider, 1991) for this purpose. The basic goal in the study of policy networks is the structural description of the actors and the analysis of relational configurations or 'actor constellations' (Scharpf, 1997) that are involved in the making of (primarily) public policies. A policy study using the network approach should, first, delineate the set of relevant actors engaged (boundary specification) and, second, identify the relations among the actors which are of particular significance and consequence for the policy outcome. Relevant relations may be the exchange of information and expertise (e.g. legal advice), the signaling of interest positions for coalition building, or the mutual support by financial and personal resources. The guiding idea behind this analytical perspective is that a certain policy may be explained by the structured interaction within the actor set. Structuring then is understood as an emergent effect which restricts as well as enables. For this task, policy network analysis borrows a number of formal concepts and statistical measures from the general methodological toolkit of social network analysis. ${ }^{16}$

Among the broad spectrum of network analytic methods we may distinguish between two types of structural analysis which are pursued at three different levels. On the one hand, there are structural methods aiming at a detailed description of whether and how the different actors in the network are connected to each other via direct and/or indirect links of communication, support, or other flows of policy resources. This may be called the connectedness perspective. The other type of structural analysis is less interested in whether actors are directly or indirectly connected, but more in the similarity or dissimilarity of the profiles of the relations in which an actor is involved. Actors with an identical or nearly identical profile are said to have structurally equivalent network positions. Both types of structural analysis may be used to analyse quite different aspects of the overall network.

For a structural description at the actor level there is a bunch of methods measuring the relative positioning of actors based on their direct and indirect ties to all other actors in the network. On the basis of graph theoretical notions (e.g. reachability, path distance, and degree) some concepts try to assess how central or peripheral in a communication structure an actor is. Others rely more on techniques stemming from input-

16. For a comprehensive summary of social network analysis, its levels of analysis and its methodological tools see Wassermann and Faust (1994) or Scott (1991). 
output analysis or status measurement in sociometry, to derive concepts indicating the 'prestige' or the 'prominence' of an actor in an overall actor constellation.

At the next level, analysis is focused on the question of how a given network is structurally partitioned into subnetworks or subgroups. Such differentiations are possible from a connectedness perspective as well as from a profile perspective. The identification of subgroups based on connectedness aims to find collections of actors who cluster together more cohesively than others. For instance, it tries to discover whether the network is integrated or whether it is segregated into two or more subsets where the subunits have more intensive internal relations. Related questions are: how many such subsets exist and how closely are these actors connected to each other in each subset? Operational concepts that are helpful for this analysis are components, cliques, clans, cores, on the one hand, but also special locational properties such as the position as a 'bridge' or a 'broker' in a network linking the subgroups to each other. In contrast, subgrouping based on profile similarity tries to find 'blocks' of structurally equivalent actors, i.e. actors with identical or highly similar profiles of relations. A block then is interpreted as a social position fulfilling specific roles in an overall network. For the identification of these blocks, social network analysis provides for a still growing spectrum of aggregation and division methods (i.e. block modeling or cluster procedures).

At the highest network level, structural analysis tries to discover the overall characteristics of the complete network structure such as how dense or how centralized it is. For this purpose it uses concepts such as density or centralization to obtain aggregate measures of the total network that are useful for comparative analysis.

Since the structure of a given policy network is analysed through specific measures of various structural properties, visualization should make these properties visible. In order to better understand the possibilities and limitations of graphical design to convey the relevant information, typical policy network substance is grouped into two main categories with four subcategories each (see Table 1). These distinctions serve as a guideline for how visualization can enhance the understanding of complex multi-dimensional settings by separating different kinds of information.

The first of the two main categories comprises those measures which are solely dependent on the presence or absence of network links. They are the network's syntactical attributes, because they are completely determined by the underlying network structure. On the other hand, there are properties which do not depend on the relationships constituting the network. These are the semantic attributes, because they relate elements of the abstract graph to their real counterparts. Since they are closely related to the actual study, only examples of such attributes can be given. 
Table 1. Principal Substance of a Network

\begin{tabular}{lc}
\hline Syntactical Attributes & Semantic Attributes \\
\hline $\begin{array}{l}\text { Derived attributes of actors } \\
\text { Centrality (undirected networks) }\end{array}$ & $\begin{array}{c}\text { Attributes of actors, e.g. } \\
\text { size of an organization } \\
\text { Prestige / prominence (undirected } \\
\text { networks) }\end{array}$ \\
age of organization \\
Structural partitions & Attribute partitions, e.g. \\
Cohesive subgroups & organizational subunits \\
Structurally equivalent actors & legal form of a policy actor \\
Role-equivalent actors & attitudes towards policy issues \\
Derived network attributes & Network attributes, e.g. \\
Size & period of data gathering \\
Density & reliability \\
Centralization & differentiation \\
Inclusiveness & \\
Cohesiveness & \\
Selected structural roles & Selected attributes, e.g. \\
Bridge & distinct institutional role such as political \\
Broker & leader \\
\hline
\end{tabular}

The first three subcategories in both columns of Table 1 correspond to the three levels of interest: actor, group, and network. ${ }^{17}$ In policy network analysis, one is often interested in all three levels of aggregation simultaneously in order to explore or communicate properties in their context. Most desirable visualization techniques therefore combine the associated perspectives in an information-dense design that allows us to switch between detail levels within a single image. In other words, they should allow for the kind of micro/macro reading described in Tufte (1990).

\subsection{Graphical Design}

The graphical design of network visualization is the specification of how a network's substance would best be represented in graphical form. In mathematical terms, such specification corresponds, in general, to a constrained optimization problem, and it is hence the purpose of a design to specify the constraints and the objective function for this problem. Consequently, an algorithm would ideally produce a graphical representation

17. A fourth subcategory is introduced in order to account for properties which apply only in special cases. For example, every actor has a centrality score, and every actor belongs to some group or not, but it need not be shown, for almost every actor, that the actor is not a broker. 
satisfying all constraints and scoring optimally on the objective function. See Section 4.3 for more details on the algorithmic problem.

The formal model of a policy network is the mathematical notion of a graph. A finite set of vertices represents the actors, while relations between actors are modeled by edges. Each edge corresponds to a link between two actors. Semantic attributes as defined in Section 4.1 correspond to labels assigned to vertices, edges, or subsets of either, respectively.

A graphical design maps the formal network model to a formal description of its graphical presentation. According to graphic designer Jacques Bertin (1983; see also Mackinlay, 1986), a graphical presentation consists of marks (points, lines, areas, and, possibly, volume objects), i.e. zero- to three-dimensional objects, for which positional ( $x$-, $y$-, and, possibly, $z$-coordinates), retinal (size, shape, orientation, texture, color, brightness, and transparency), and temporal ${ }^{18}$ (in animation) properties are varied. Krampen (1990) advises restricting the grade of variation to perceivable differences.

The fundamental decision in a graphical design specification is the choice of a representation format. That is, one has to choose what kind of marks are to represent which elements of the network model. From the many conceivable representations of graphs, arguably the most familiar consists of points depicting vertices (actors) and lines depicting edges (links). ${ }^{19}$ Sociograms and scattergrams (where edges are typically omitted) are members of the corresponding class of diagrams. Subclasses of this representation are obtained by globally fixing selected properties. For instance, the shape of lines representing edges could be 'straight' (straightline representation) or 'axis-parallel segments' (orthogonal representation). If the actor positions are fixed to lie equally spaced on a circle, the representation obtained is a circle diagram.

Positional, retinal, and temporal properties of marks need to be specified in accordance with the network's substance. Additionally, ergonomic aspects have to be considered to ease perception. According to the respective classes of properties, we subdivide the design specification into layout specification (positional properties), rendering specification (retinal properties), and animation (temporal properties). The structure of a design specification is summarized in Figure 6.

18. Since we are, in this article, concerned with the classical case of static networks only, we do not go into detail about temporal properties.

19. Other types of representations are in use, too. Consider, for instance, a hierarchy in which each element has exactly one superordinate element. Each element of such hierarchy can be represented by an area containing the areas corresponding to subordinate elements. As is the case with many other representations, only graphs of certain structures can be visualized in this way. This representation is called inclusion drawing and is closely related to the Venn diagram. 


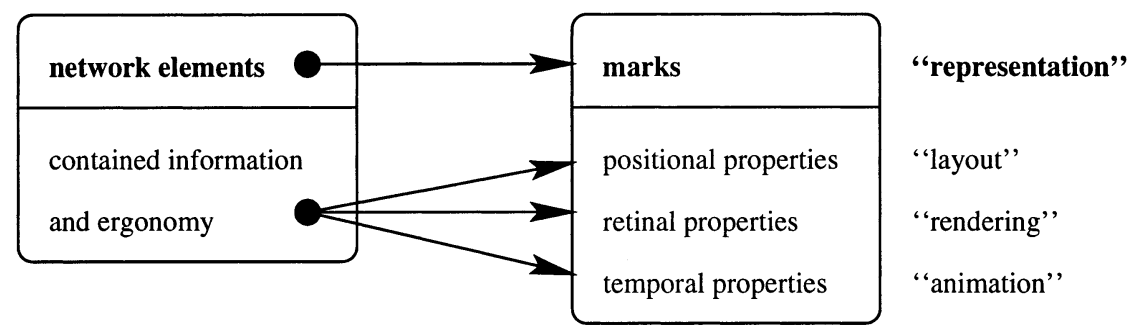

Figure 6. Specification of a Graphical Design

Layout. Consider a straight-line representation of a graph. Since all edges are represented by straight lines connecting their end vertices, it is sufficient to have coordinates for these. A layout specification does not fix these coordinates, but states their desirable features. For example, the design might state that two actors connected by a link should be placed at some particular distance, that is, their coordinates are not set to a certain value, but they are constrained to fulfill a certain relation.

In general, graphical design specifies desirable features of coordinates for a number of marks representing elements like vertices, edge bends, or labels. Given a certain form of representation, it must be possible to determine positional properties of marks representing other elements in the network model from those for which a design is specified. Blythe et al. (1995) observed that the layout of a network has considerable effect on the perception of network substance.

We distinguish two ways of specifying desirable positional properties. The first is to restrict the set of admissible layouts by imposing design constraints. Every assignment of coordinates then has to satisfy properties expressed in terms of constraints. A straightforward example is egocentered networks, where it is reasonable to fix the position of the ego to lie in the center of the drawing. Another example is a hierarchy, where subordinates are placed beneath their superordinates. It is not always possible to clearly separate representational from design constraints.

However, some desirable features may result in constraints that are not satisfiable. For instance, most networks do not admit a layout with equal distance between any pair of linked actors. A design criterion is a function that assigns, to a given layout, a value reflecting the layout's conformance to some design goal. Criteria can be viewed as relaxed constraints that are to be satisfied in the best possible way, but not necessarily fully: the higher the conformance score is the better the layout is. In general, there is more than one criterion for effective display of substance (like uniform edge length, subgroups being visually separable, central actors being close to the 
center of the drawing) and ergonomic readability (like uniform vertex distribution, small total area, small number of edge crossings). Most of the time imposed criteria conflict, so a perfect layout does not optimize each criterion in isolation but rather their combination. In this combination, criteria might be weighted according to their relative importance. A generic mathematical model for layout design and generation is given by Brandes and Wagner (1997).

Rendering. In a sociogram, instead of points or circles, one might want to have names or logos for actors constituting the nodes, line thickness might be varied to indicate different strengths of ties, or polygons separating subgraphs might be desired in order to distinguish structural subgroups. Such rendering rules do not alter a representation, or positional properties of its marks, but only its visual appearance, i.e. retinal properties. We do not go into further detail here, since it seems to us that the issue of rendering a presentation of relational data does not differ as much from the rendering of other data as does its layout. Therefore, most research in visualization of categorical data also applies to the rendering of relational data (see e.g. Tufte, 1983).

It seems to be a reasonable rule of thumb that syntactical attributes should be displayed mostly by positional properties of graphical marks, while semantic attributes should determine the retinal properties. Such a distinction also supports the development of a general tool for network visualization, since, in general, it is easier to customize a program's rendering capabilities than its layout features.

\subsection{Algorithmic Realization}

Given a network model and a graphical design specification, a drawing has to be generated according to the requirements manifested in the design. The procedure used to generate the drawing is called algorithmic realization of the design. Since the representation is fixed in the design, the algorithm has to compute a layout, render, and possibly animate it.

Typically, the rules contained in a rendering specification do not result in conflicting requirements. A reasonable rendering specification should thus not pose problems in terms of its algorithmic realization.

Quite conversely, almost every layout specification leads to a difficult optimization problem. A layout generated by the algorithm has to satisfy every constraint, as well as to optimize the weighted sum of all criteria. Such requirements are often intractable, if the algorithm is to generate an output in reasonable time. In this case, approximate solutions are sought. A well known and fairly successful procedure for mostly unconstrained designs is simulated annealing (Metropolis et al., 1953). A prominent 
software using this type of algorithm is КRACKPLOT (Krackhardt et al., 1994). When applying simulated annealing, the objective function of a design is considered to be the energy of a physical system. A probabilistic sequence of layouts that change moderately from one layout to the other is produced according to some generation scheme that simulates the behavior of the physical system in a heat bath for slow annealing. Note that different results may be produced in different runs of an algorithm. This is obvious for probabilistic methods like simulated annealing, but it also holds for many deterministic methods that depend on the initial configuration.

We stress again the importance of clearly identifying and distinguishing a design and its algorithmic realization. For example, Freeman (1996) compares a layout algorithm from the graph drawing community (Kamada and Kawai, 1989) with an algorithm implemented in KrACKРцOT. He states that the spring embedder variant of Kamada and Kawai 'is based on an assumed "attraction" between adjacent points and a "repulsion" between non-adjacent points' (Freeman, 1996), while the algorithm in KRACKPLOT 'employs synthetic annealing to minimize the distance of each point from all the others to which it is adjacent' (Freeman, 1996). These appear to be quite different approaches because, in the first case, a physical analogy is used to describe the design, while in the second case, some other physical analogy is used to describe the applied algorithm. However, both designs are strongly related. And even though different algorithms are employed, both do sufficiently realize the design. It hence comes as no surprise at all that 'the arrangement produced [...] is quite similar' (Freeman, 1996).

\section{Example}

In this section, we use a network analysed by Doreian and Albert (1989) to exemplify some of the issues we have raised in the previous sections (cf. Figures 1 and 3). We therefore point out what is chosen to be the network's substance, devise a design, indicate some algorithmic aspects, and discuss the result shown in Figure 7. Note that the example is set up so that it gives a visualization which is illustrative, but far from excellent.

Doreian and Albert hypothesized that the actors can be partitioned into two camps, based on their strong political ties. To visualize their findings, they used an MDS scattergram based on path distances. Hence, for the purpose of this example, we define the substance of the network to be, on the first level of aggregation (actor level), the degree of closeness centrality, ${ }^{20}$ and on the second level of aggregation (subnetwork level), a partitioning into cohesive subgroups. Note that we do not employ a formal measure

20. Regarding this interpretation see also Krempel (1993: 10). 


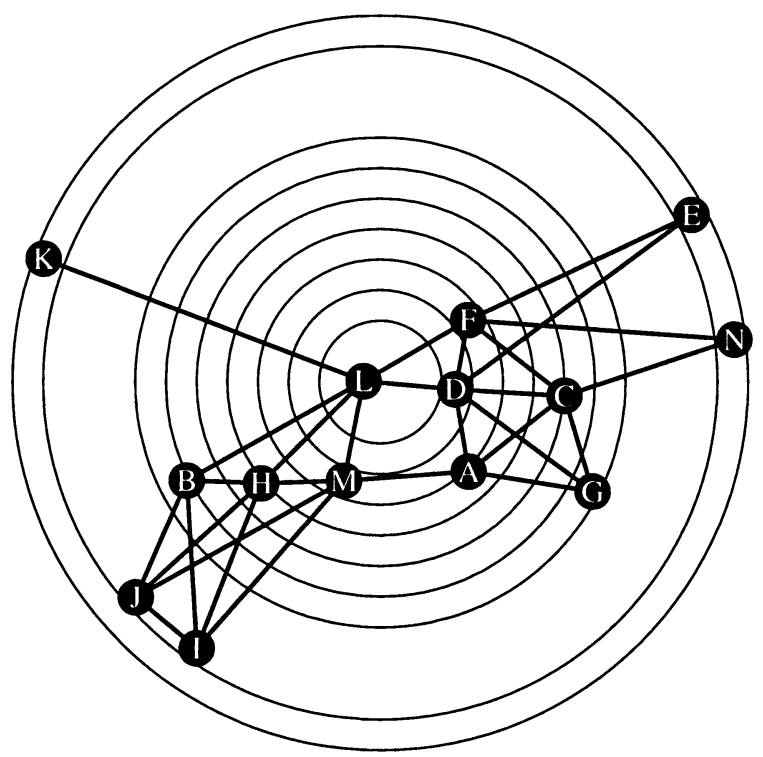

levels of centrality

\begin{tabular}{c|c}
$\mathrm{L}$ & 18 \\
& 19 \\
$\mathrm{D}$ & 20 \\
$\mathrm{~F}, \mathrm{M}$ & 21 \\
$\mathrm{~A}$ & 22 \\
$\mathrm{H}$ & 23 \\
$\mathrm{C}$ & 24 \\
$\mathrm{~B}$ & 25 \\
$\mathrm{G}$ & 26 \\
& 27 \\
$\mathrm{I}, \mathrm{J}$ & 28 \\
$\mathrm{E}, \mathrm{K}, \mathrm{N}$ & 29 \\
\end{tabular}

Figure 7. A Centrality Oriented Layout of the Graph from Figures 1 and 3

of cohesiveness, but incorporate an interpretation of cohesiveness into the design specification. Any other substance is considered to be of minor interest.

To specify the design formally, some more terminology is needed. Let $G$ $=(V, E)$ be the graph associated with the (informal) network, where $V$ is the set of actors, and $E$ the set of pairs of actors indicating who has strong political ties to whom. Let us say that we want to visualize the network using a two-dimensional straight-line representation. Then, actors are represented by points, links by lines with property shape fixed to 'straight', and labels by points. We now need to specify the objective function of the layout, and give a set of rendering rules.

Assuming that actor labels are shown at the center of each node, the positional properties of all marks are completely determined by an assignment of coordinates $x_{v}$ to all actors $v \in V$. Here, we do not restrict the set of possible assignments, so every vector $x=\left(x_{v}\right) v \in V$ of actor positions constitutes a feasible layout. An objective function $U(x)=U_{1}(x)$ $+U_{2}(x)+U_{3}(x)$ is used to determine layout quality. It incorporates the following design rules:

spread actors evenly in the plane: $U_{1}(x)=\sum_{u \neq v \in V} c_{1} / d\left(x_{u}, x_{v}\right)^{2}$;

place adjacent actors close to each other: $U_{2}(x)=\sum_{\{u, v\} \in E} c_{2} \cdot d\left(x_{u}, x_{v}\right)^{2}$; 
place actor $v$ with centrality score $C_{v}$ at distance proportional to $C_{v}-$ $\max _{u \in V} C_{u}$ from the center $\zeta$ of the drawing: $U_{3}(x)=\sum_{v \in V} c_{3} \cdot\left(d\left(x_{v}, \zeta\right)-\right.$ $\left.c_{4} \cdot\left(C_{v}-\max _{u \in V} C_{u}\right)\right)^{2}$

where $c_{1}$ and $c_{2}$ are constants controlling the scale of distances, $c_{3}$ is a constant controlling the relative influence of $U_{3}(x)$, and $d\left(x_{u}, x_{v}\right)$ denotes the Euclidean distance between positions $x_{u}$ and $x_{v}$. Since $U(x)$ attains higher values for worse layouts, $U(x)$ should be minimized to obtain a layout that conforms to our design specification. Note that we also assigned points to centrality levels. They are positioned in the center of the drawing, while their shape is set to 'circle', and their size is to reflect the level of centrality. In a similar way, a stem-and-leaf diagram of centrality scores was integrated to the right. The rendering rules used in this example are readily observed from Figure 7.

We used an annealing type algorithm to (approximately) minimize $U(x)$, and the built-in rendering capabilities of GRAPHWIN, a graph editor included in LEDA ${ }^{21}$ (Mehlhorn and Näher, 1997).

Discussion. In the example, a number of important aspects have been made obvious. The most important is that one readily observes that the assignment of positions in the layout is a compromise between conflicting design goals. The constants have been chosen such that lying close to the correct radius is six times as important as lying close to an adjacent actor. Actor positions could be restricted to lie exactly at the correct radius but, in this case, the goal of uniform edge length (the truth to the data principle) would be violated even more (e.g. actors $\mathrm{K}$ and L). ${ }^{22}$ Due to the number of accumulated conflicts, the deviation from their radius is larger for central actors than for peripheral ones.

Next, we did not include more sophisticated ergonomic criteria like sufficient edge-to-vertex distance or small number of crossings. In the example there are two links unnecessarily close to actors $\mathrm{F}$ and $\mathrm{H}$, respectively. Furthermore, the graph can be drawn with a minimum of one pair of crossing lines (see Figure 1). It has been shown that crossings might hamper structural understanding (Purchase et al., 1995). On the other hand, a straight-line representation of a clique of four actors must place one of them in the middle in order to avoid crossing lines, wrongly suggesting a higher degree of centrality (compare actors A, C, D, and G in Figures 1 and 7).

More elaborate rendering could improve on clarity and the amount of

21. Library of Efficient Datatypes and Algorithms. See http://www.mpi-sb.mpg.de/LEDA/ leda.html

22. Observe that the optimal edge length implied by the expressions contributing to $U_{1}(x)$ and $U_{2}(x)$ is $\sqrt[4]{c_{1} / c_{2}}$, i.e. constant over all edges. 
information displayed. For example, seven actors are County Council members, which is, in the analytical context of this network, relevant information that is easily indicated by altering the color property of their marks.

Despite these drawbacks, two easily identified camps are visible, which have not been preassigned in the design. Note that it would be easy to suggest arbitrary grouping by simply moving members of different groups apart (McGrath et al., 1997). Moreover, the most central actor (L) is clearly visible. The fact that one of the most peripheral actors $(\mathrm{K})$ is directly linked to $L$ results in a very long edge, suggesting that closeness centrality might not reflect the intuitive notion of an actor being influential in a political network.

\section{Conclusion}

There is a remarkable discrepancy between, on the one hand, the potential of visualization techniques in the description, presentation, and exploration of policy networks and, on the other hand, the interest, experience, and techniques available for producing effective visualizations. Consequently, this article aimed to bridge this discrepancy by arguing that it is worthwhile reflecting about the effective visualization of policy networks. The article has illustrated that a number of procedures and associated computer programs exist which allow for the visualization of policy networks but that there is little discussion of their usefulness, nor are hints given by their users and producers on the effectiveness of the visualizations.

Consequently, this article has identified three dimensions which help to evaluate the effectiveness of the visualization of policy networks: substance, design, and algorithm. It argues that effective visualization is a combination of providing an algorithmic solution to a substantive problem in such a way that basic design principles are respected. In other words each of the dimensions should consider as far as possible the principles set by the other two. In a time in which there is a rapid increase in the availability of computing power and quality graphic equipment, one can expect a similar increase in the use of graphical output in both research and communication. It is hence important to be able to assess the quality of graphical presentations.

A short review reveals that all three dimensions are almost never considered sufficiently. Visualization tools tend to exclusively concentrate on one of them, leading to an uncontrolled determination of the other two. It seems that most of the visualizations of policy networks are, in the first place, the result of applying an algorithm which was developed for the communication of a very different type of information. As spelled out in the article, policy networks are, however, phenomena which have to be 
described in very specific terms in order to discover significant and useful information about them.

Since the formal concepts of policy network analysis are well established, the next step is to devise principles for an effective design on the basis of this substance. The major problem here is the positioning of actors, i.e. the layout of the network. It can be expected that most design goals will contradict each other (as in the centrality/edge length trade-off in Section 5). A possible approach is to combine different forms of visualization in order to 'triangulate' different analytical perspectives. Each should provide greater accuracy in the description of selected aspects, while their combination diminishes the risk of being misled by a methodological artifact. ${ }^{23}$

To come up with specific design principles for the visualization of policy networks, much more research is needed, drawing on general insights into the visualization of quantitative information, general semiotic principles, and experimental validations. It is our hope that algorithms for the resulting designs will be able to produce pictures which tell us more than just how complicated this world is.

\section{REFERENCES}

Batagelj, W. and A. Mrvar (1997) 'A Package for Analyzing Large Networks', Paper presented at Sunbelt XVII, San Diego.

Bertin, J. (1983) Semiology of Graphics: Diagrams, Networks, Maps. Madison, WI: University of Wisconsin Press.

Blythe, J., C. McGrath and D. Krackhardt (1995) 'The Effect of Graph Layout on Inference from Social Network Data', in F. J. Brandenburg (ed.) Proceedings of the Third Symposium on Graph Drawing, Lecture Notes in Computer Science Vol. 1027, pp. 40-51. Berlin: Springer.

Börzel, T. A. (1997) Policy Networks. A New Paradigm for European Governance?, EUI Working Paper RSC 97/19. San Domenico, Florence: European University Institute.

Brandes, U. and D. Wagner (1997) 'A Framework for Graph Layout', Paper presented at the Second Workshop 'Bits - Bilder - Bedeutung', Bielefeld.

Conran, T. (1996) Terence Conran on Design. London: Conran Octopus.

Di Battista, G., P. Eades, R. Tamassia and I. G. Tollis (1994) 'Algorithms for Drawing Graphs: An Annotated Bibliography', Computational Geometry 4: 235-82.

Doreian, P. (1988) 'Using Multiple Network Analytic Tools for a Single Social Network', Social Networks 10: 287-312.

Doreian, P. and L. H. Albert (1989) 'Partitioning Political Actor Networks: Some Quantitative Tools for Analyzing Qualitative Networks', Journal of Quantitative Anthropology 1: 279-91.

Eades, P. (1984) 'A Heuristic for Graph Drawing', Congressus Numerantium 42: 149-60.

Freeman, L. C. (1996) 'Visualizing Social Networks', manuscript; available from http:// carnap.ss.uci.edu/vis.html

23. Triangulation is generally defined as the combination of methodologies in the study of the same phenomenon. It stems from a military metaphor pointing to the use of multiple reference points to locate an object's exact position (Jick, 1979: 602). For an implicit use of triangulation in network analysis see Doreian (1988). 
Freeman, L. C. (1997) 'Using Molecular Modeling Software in Social Network Analysis: A Practicum', Manuscript; available from http://eclectic.ss.uci.edu/ lin/chem.html

Héritier, A. (1993) 'Policy-Netzwerkanalyse als Untersuchungsinstrument im Europäischen Kontext: Folgerungen aus einer empirischen Studie regulativer Politik', in A. Héritier (ed.) Policy-Analyse, pp. 432-450. PVS-Sonderheft, Opladen: Westdeutscher.

Jick, T. D. (1979) 'Mixing Qualitative and Quantitative Methods: Triangulation in Action', Administrative Science Quarterly 24: 602-11.

Johnson, D. S. (1982) 'The NP-Completeness Column: An Ongoing Guide', Journal of Algorithms 3: 89-99.

Kadushin, C. (1974) The American Intellectual Elite (Computer Program developed by Richard Alba). Boston: Little, Brown.

Katz, L. (1947) 'On the Matric Analysis of Sociometric Data', Sociometry 10: 233-41.

Kenis, P. and V. Schneider (1991) 'Policy Networks and Policy Analysis: Scrutinizing a New Analytical Toolbox', in B. Marin and R. Mayntz (eds) Policy Networks. Empirical Evidence and Theoretical Considerations, pp. 25-59. Frankfurt/M.: Campus.

Klovdahl, A. S. (1981) 'A Note on Images of Networks', Social Networks 3: 197-214.

Klovdahl, A. S. (1986) 'ViewNet: A New Tool for Network Analysis', Social Networks 8: 31342.

Knoke, D., ed. (1990a) Political Networks. The Structural Perspective. Cambridge: Cambridge University Press.

Knoke, D. (1990b) 'International Relations' (written with Jodi Burmeister-May), in D. Knoke, Political Networks. The Structural Perspective, pp. 175-202. Cambridge: Cambridge University Press.

Krackhardt, D., J. Blythe and C. McGrath (1994) 'KrackPlot 3.0: An Improved Network Drawing Program', Connections 17(2): 53-5.

Krampen, M. (1990) 'Visual Communication and Semiotics', in W. Koch (ed.) Semiotics in the Individual Sciences (Part 2), pp. 486-512. Bochum: Brockmeyer.

Krempel, L. (1993) 'Simple Representations of Complex Networks: Strategies for Visualizing Network Structure', Paper presented at the 3rd European Conference for Network Analysis, München.

Krempel, L. (1997) 'A Gallery of Social Structures', Max-Planck-Institut für Gesellschaftsforschung. Köln; http://www.mpi-fg-koeln.mpg.de/ lk/netvis.html

Kriesi, H. (1982) 'The Structure of the Swiss Political System', in Ph. Schmitter and G. Lehmbruch (ed.) Patterns of Corporatist Policy-Making, pp. 133-63. Beverly Hills: Sage.

Kruskal, J. B. and M. Wish (1978) Multidimensional Scaling. Beverly Hills: Sage.

Laumann, E. O. (1966) Prestige and Association in an Urban Community. Indianapolis: Bobbs-Merrill.

Laumann, E. O. and D. Knoke (1987) The Organizational State. Social Choices in National Policy Domains. Madison, WI: University of Wisconsin Press.

Laumann, E. O. and F. U. Pappi (1976) Networks of Collective Action: A Perspective on Community Influence Systems. London: Academic Press.

Levin, M. L. (1976) 'Displaying Sociometric Structures: An Application of Interactive Computer Graphics for Instruction and Analysis', Simulation and Games 7: 295-310.

McGrath, C., J. Blythe and D. Krackhardt (1997) 'Seeing Groups in Graph Layouts', Manuscript; available from http://www.andrew.cmu.edu/user/cm3t/groups.html

Mackinlay, J. D. (1986) 'Automating the Design of Graphical Presentations of Relational Data', ACM Transactions on Graphics 5(2): 110-41.

Manigart, Ph. (1986) Les Relations Inter-Organisationelles dans le Domaine de la Défense Nationale. Brussels: Centre de Recherche et d'Information Socio-Politiques.

Mayntz, R. (1993) 'Networks, Issues, and Games: Multiorganisational Interactions in the Restructuring of a National Research System', in F. Scharpf (ed.) Games in Hierarchies and 
Networks. Analytical and Empirical Approaches to the Study of Governance Institutions, pp. 189-210. Frankfurt/Boulder, CO: Westview/Campus.

Mayntz, R. (1994) Deutsche Forschung im Einigungsprozeß. Die Transformation der Akademie der Wissenschaften der DDR 1989 bis 1992, Frankfurt/New York: Campus.

Mehlhorn, K. and S. Näher (1997) LEDA: A Platform for Combinatorial and Geometric Computing, Cambridge: Cambridge University Press.

Metropolis, N., A. W. Rosenbluth, M. N. Rosenbluth, A. H. Teller and E. Teller (1953) 'Equation of State Calculations by Fast Computing Machines', The Journal of Chemical Physics 21(6): 1087-92.

Mohar, B. (1991) 'The Laplacian Spectrum of Graphs', in Y. Alavi et al. (eds) Graph Theory, Combinatorics, and Applications, pp. 871-98. New York: Wiley.

Moreno, J. L. (1953) Who Shall Survive: Foundations of Sociometry, Group Psychotherapy and Sociodrama. Beacon, NY: Beacon House.

Müller, K. H. (1991) Symbole, Statistik, Computer, Design. Wien: Hölder-Pichler-Tempsky.

Northway, M. L. (1940) 'A Method for Depicting Social Relationships Obtained by Sociometric Testing', Sociometry 3: 144-50.

Pappi, F. U. (1995) 'Macht in Politikfeld-Netzen: Die Beziehungen zwischen arbeits- und sozialpolitischen Akteuren der Bundesrepublik im internationalen Vergleich', in K.-H. Reuband et al. (eds) Die deutsche Gesellschaft in vergleichender Perspektive. Festschrift für Erwin K. Scheuch zum 65. Geburtstag. Opladen: Westdeutscher.

Pappi, F. U., Th. König and D. Knoke (1995) Entscheidungsprozesse in der Arbeits- und Sozialpolitik. Der Zugang der Interessengruppen zum Regierungssystem über Politikfeldnetze. Ein deutsch-amerikanischer Vergleich. Frankfurt/New York: Campus.

Purchase, H. C. (1997) 'Which Aesthetic has the Greatest Effect on Human Understanding?', in G. D. Battista (ed.) Proceedings of the Fifth Symposium on Graph Drawing, Lecture Notes in Computer Science Vol. 1353, pp. 248-61. Berlin: Springer.

Purchase, H. C., R. F. Cohen and M. James (1995) 'Validating Graph Drawing Aesthetics', in F. J. Brandenburg (ed.) Proceedings of the 3rd Symposium on Graph Drawing, Lecture Notes in Computer Science 1027, pp. 435-46. Berlin: Springer.

Richards, W. and A. Seary (1997) 'Introduction to Eigen Analysis of Networks', Paper presented at Sunbelt XVII, San Diego; available from http://www.sfu.ca/ richards/ wdr97.htm

Roethlisberger, F. J. and W. J. Dickson (1939) Management and the Worker. Cambridge, MA: Harvard University Press.

Scarini, P. (1996) 'Elaboration of the Swiss Agricultural Policy for the Gatt Negotiations: A Network Analysis', Swiss Journal of Sociology 22(1): 85-115.

Scharpf, F. W. (1997) Games Real Actors Play. Actor-Centered Institutionalism in Policy Research. Boulder, CO: Westview.

Schneider, V. (1988) Politiknetzwerke der Chemikalienkontrolle. Eine Analyse einer transnationalen Politikentwicklung. Berlin: De Gruyter.

Schneider, V. (1992) 'The Structure of Policy Networks. A Comparison of the "Chemicals Control" and "Telecommunications" Policy Domains in Germany', European Journal of Political Research 21: 109-29.

Schneider, V. (1993) 'Networks and Games in Large Technical Systems. The Case of Videotext', in Scharpf, F. (ed.) Games in Hierarchies and Networks. Analytical and Empirical Approaches to the Study of Governance Institutions, pp. 251-86. Frankfurt/ Boulder, CO: Westview/Campus.

Schneider, V. and R. Werle (1991) 'Policy Networks in the German Telecommunications Domain', in B. Marin and R. Mayntz (eds) Policy Networks: Empirical Evidence and Theoretical Considerations, pp. 97-136. Frankfurt/Boulder, CO: Campus/Westview.

Scott, J. (1991) Social Network Analysis: A Handbook. London/Newbury Park: Sage. 
Tufte, E. R. (1983) The Visual Display of Quantitative Information. Cheshire, CT: Graphics Press.

Tufte, E. R. (1990) Envisioning Information. Cheshire, CT: Graphics Press.

Wassermann, S. and K. Faust (1994) Social Network Analysis. Methods and Applications. Cambridge: Cambridge University Press.

ULRIK BRANDES received his Diplom degree in computer science from the Rheinisch-Westfälische Technische Hochschule Aachen in 1994 and is currently a PhD candidate at the University of Konstanz. Research interests center around graph algorithms and visualization. ADDRESS: Faculty of Mathematics and Computer Science, University of Konstanz, 78457 Konstanz, Germany.

[email: Ulrik.Brandes@uni-konstanz.de]

PATRIK KENIS graduated as Doctor of Political and Social Science in 1989 from the European University Institute in Florence. From 1988 to 1994 he was Researcher and Programme Director at the European Center for Social Science Welfare Policy Research (institute affiliated to the United Nations) in Vienna. Since 1994 he has been assistant professor at the Faculty of Public Policy and Management at the University of Konstanz where he teaches policy and organization analysis, especially in the areas of health and welfare. ADDRESS: Faculty of Public Policy and Management, University of Konstanz, 78457 Konstanz, Germany.

[email: Patrick.Kenis@uni-konstanz.de]

JÖRG RAAB is a PhD candidate at the Faculty of Public Policy and Management at the University of Konstanz. His research focuses on institutional coordination of political and economic activity. He is currently writing his dissertation on the governance structures of politicized privatization in East Germany. ADDRESS: Faculty of Public Policy and Management, University of Konstanz, 78457 Konstanz, Germany.

[email: Joerg.Raab@uni-konstanz.de]

VOLKER SCHNEIDER studied management, economics, and political science in Mainz, Berlin, and Paris, receiving degrees in business management, economics, and political science. From 1982 to 1986 he was at the European University Institute in Florence, receiving his PhD there in 1986. From 1986 to 1997 he was research fellow at the Max-Planck-Institut in Cologne. Since 1997 he has been full professor of political science at the Faculty of Public Policy and Management at the University of Konstanz. His special research interests are state and interest group theory, policy analysis, network analysis, and telecommunications policy. ADDRESS: Faculty of Public Policy and Management, University of Konstanz, 78457 Konstanz, Germany.

[email: Volker.Schneider@uni-konstanz.de]

DOROTHEA WAGNER received her Diplom and PhD degrees in mathematics from the the Rheinisch-Westfälische Technische Hochschule Aachen 
in 1983 and 1986, respectively. In 1992, she received her Habilitation degree from the Department of Mathematics at the Technische Universität Berlin. Since 1994 she has been a full professor of computer science at the University of Konstanz. Research interests are in the areas of discrete optimization and graph algorithms, particularly as applied to graph drawing, VLSI design, communication networks, and transportation systems. She is a member of the editorial board of the Journal of Graph Algorithms and Applications. ADDRESS: Faculty of Mathematics and Computer Science, University of Konstanz, 78457 Konstanz, Germany.

[email: Dorothea.Wagner@uni-konstanz.de] 